\title{
A novel variant of $I H H$ in a Chinese family with brachydactyly type 1
}

\author{
Qi Yang ${ }^{1}$, Jin Wang ${ }^{1}$, Xiaoxian Tian², Fei Shen ${ }^{1}$, Jing Lan ${ }^{3}$, Qiang Zhang ${ }^{1}$, Xin Fan ${ }^{1}$, Shang Yi ${ }^{1}$, Mengting Li ${ }^{1}$ and \\ Yiping Shen ${ }^{1,4,5^{*}}$
}

\begin{abstract}
Background: Brachydactyly type $\mathrm{A} 1(\mathrm{BDA}-1)$ is an autosomal dominant disorder which is caused by heterozygous pathogenic variants in a specific region of the N-terminal active fragment of Indian Hedgehog $(I H H)$. The disorder is mainly characterized by shortening or missing of the middle phalanges. In this study, Our purpose is to identify the pathogenic variations associated with BDA-1 involved in a five-generation Chinese family.

Methods: A BDA-1 family with 8 affected and 14 unaffected family members was recruited. Whole exome sequencing (WES) was performed to identify the pathogenic variant in the proband, and which was later confirmed and segregated by Sanger sequencing. The significance of variants were assessed using several molecular and bioinformatics analysis methods.

Results: We uncovered a novel heterozygous missense variant c.299A > G (p.D100G) at the mutational hotspot of IHH gene following whole-exome sequencing of a Chinese family with BDA-1. The variant co-segregated with BDA1 in the pedigree, showed 100\% penetrance for phalange phenotype with variable expressivity.

Conclusions: In conclusion, this study reports a five-generation Chinese family with BDA-1 due to a novel pathogenic variant (c.299A > G (p.D100G)) of $1 \mathrm{HH}$ and expands the clinical and genetic spectrum of BDA-1.
\end{abstract}

Keywords: Brachydactyly type A1, IHH gene, Variant

\section{Background}

Brachydactyly (BD) is generally characterized by shortened and often malformed digits of the hands [1]. Heritable BDs have been classified into seven types, i.e.: A1, $\mathrm{A} 2, \mathrm{~A} 3, \mathrm{~B}, \mathrm{C}, \mathrm{D}$, and $\mathrm{E}$ on the basis of their patterns of skeletal involvement [2]. Brachydactyly A-1 (BDA1; MIM 112500) is inherited as an autosomal dominant disorder and is characterized by short stature and shortening of middle phalanges of all the digits. The middle

\footnotetext{
* Correspondence: Yiping.shen@childrens.harvard.edu

${ }^{1}$ Genetic and Metabolic Central Laboratory, Birth Defect Prevention Research Institute, Maternal and Child Health Hospital, Children's Hospital of Guangxi Zhuang Autonomous Region, Nanning 530002, China

${ }^{4}$ Department of Medical Genetics and Molecular Diagnostic Laboratory,

Shanghai Children's Medical Center, Shanghai Jiao Tong University School of Medicine, Shanghai 200127, China

Full list of author information is available at the end of the article
}

phalanges are either rudimentary or fused with the terminal phalanges. About half of the BDA1 families are due to mutations in the $I H H$ (Indian Hedgehog) gene [3]. To date, about 14 different $I H H$ pathogenic variants had been identified in individuals with BDA1 (HGMD and ClinVar), and the pathogenic variants cluster in the central region of the $\mathrm{N}$-terminal signaling fragment [4]. As a central signaling molecule in mediating skeletal development, IHH plays an important role in mediating skeletal condensation, growth and differentiation of chondrocyte, joint development and bone formation [5]. Here, we studied a five-generation Chinese family associated with a variation of BDA1 and identified a novel $I H H$ pathogenic variant by whole-exome sequencing.

(c) The Author(s). 2020 Open Access This article is licensed under a Creative Commons Attribution 4.0 International License, which permits use, sharing, adaptation, distribution and reproduction in any medium or format, as long as you give appropriate credit to the original author(s) and the source, provide a link to the Creative Commons licence, and indicate if changes were made. The images or other third party material in this article are included in the article's Creative Commons licence, unless indicated otherwise in a credit line to the material. If material is not included in the article's Creative Commons licence and your intended use is not permitted by statutory regulation or exceeds the permitted use, you will need to obtain permission directly from the copyright holder. To view a copy of this licence, visit http://creativecommons.org/licenses/by/4.0/ The Creative Commons Public Domain Dedication waiver (http://creativecommons.org/publicdomain/zero/1.0/) applies to the data made available in this article, unless otherwise stated in a credit line to the data. 


\section{Materials and method Subjects}

The BDA-1 affected family was referred to Guangxi Maternal and Child Health Hospital for shortened and malformed digits and requested genetic testing for all 22 family members. Diagnosis was based on physical examination, radiographic findings and family history. There were 20 individuals tested in the BDA1-affected family including 6 individuals who were diagnosed with BDA1. In order to rule out the possibility that the variant is unique to the region, we recruited 200 local residents for alternative allele frequency testing in 2018. The control group consisted of 100 females and 100 males aged between 20 to 40 . The height of each individual in the control group was taller than $160 \mathrm{~cm}$. The fingers and toes of the control group appears normal. All participants recruited in this study provided informed consent for the study approved by the ethics committee of the Maternal and Child Health Hospital of Guangxi Zhuang Autonomous Region. The pedigree was shown in Fig. 1.

\section{Genetic analysis}

\section{Whole-exome sequencing and sanger sequencing}

Genomic DNA was extracted from peripheral blood using standard protocols of Lab-Aid DNA kit (Zeesan Biotech Co., Ltd., Xiamen, China). Agilent SureSelect Human All Exon V5 Kit (Agilent Technologies, Santa Clara, CA) was used for target capture. The library was sequenced on the Hiseq 2500 platform (Illumina, San
Diego, CA, USA) according to the manufacturer's instructions. A custom pipeline mainly built on the Genome Analysis Toolkit (GATK) was used for sequence data analysis and annotation. Identification of causal variant was aided by the TGex software (LifeMap Sciences,USA). We performed genotyping on 200 subjects by Sanger sequencing.

CADD (https://cadd.gs.washington.edu/snv; $>20$ Damaging, $\leq 2$ Tolerable 0)), SIFT (http://sift.jcvi.org/; $<0.05$ deleterious, $\geq 0.05$ tolerated), PolyPhen2 (http:// genetics.bwh.harvard.edu/pph2/; 0-0.15 Benign, 0.150.85 Possibly damaging, $0.85-1$ Probably damaging) and MutationTaster (http://www.mutationtaster.org/; disease-causing, polymorphism) were used to analyze the functional effects of novel variants with their respective cut-offs. Three-dimensional structures of wild type (WT) and mutant (MUT) IHH were predicted using SWISS-MODEL (https://swissmodel.expasy.org/ interactive) by importing WT and MUT-IHH amino acid sequences. The candidate $\mathrm{IHH}$ variant was validated by Sanger sequencing and its pathogenicity classified following ACMG/AMP Guidelines [6].

\section{Results}

\section{Clinical phenotype}

We constructed a pedigree of the five-generation family that participated in this study, which includes 6 family members affected by BDA-1, 2 affected members have been deceased, and 14 family members who are unaffected (Fig. 1,Table 1). We identified a $I H H$ variant c.299A > G / p.Asp100Gly which co-segregate

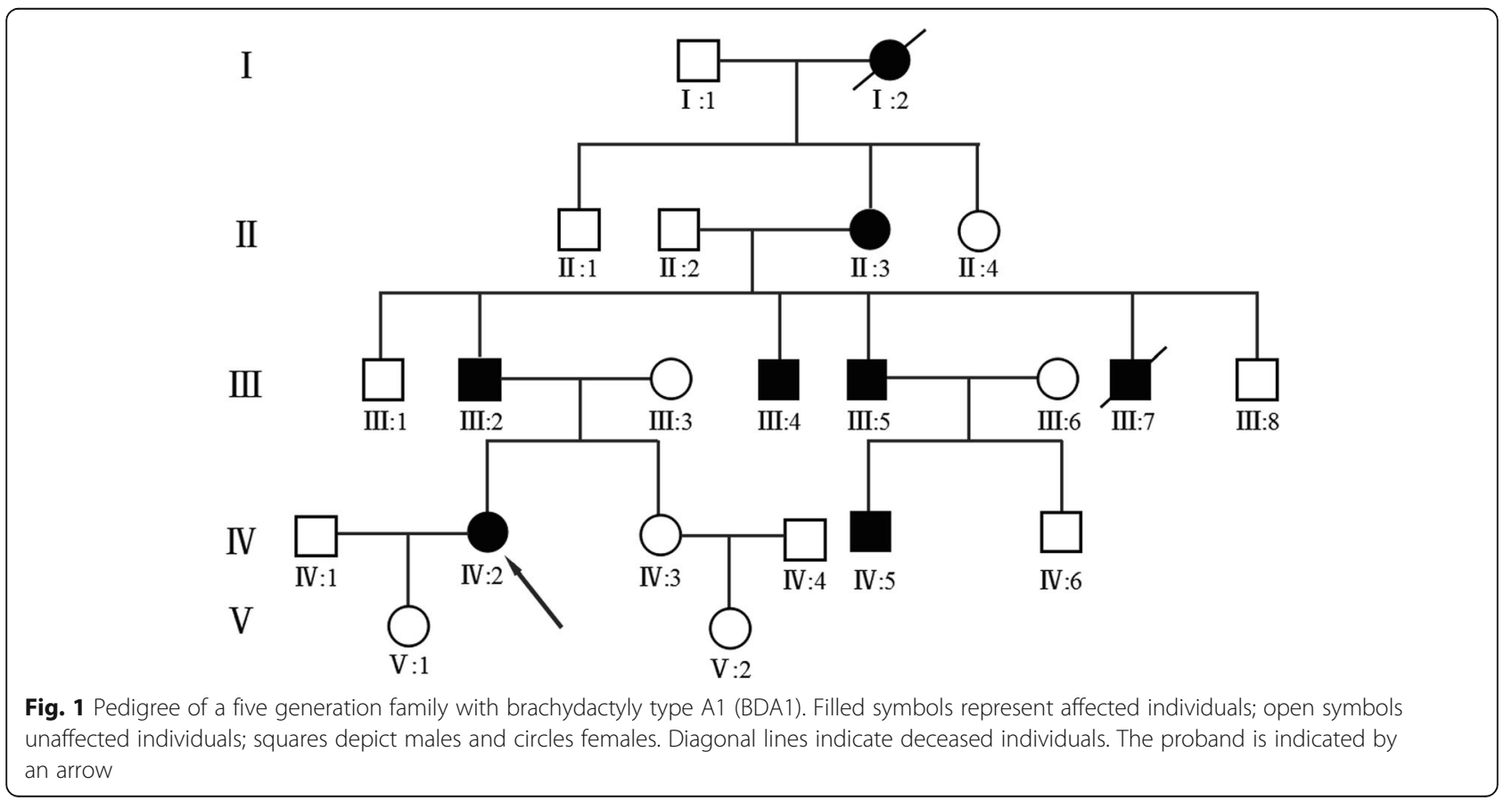


Table 1 Clinical features of the patients with de novo $\mathrm{HH}$ mutations

\begin{tabular}{|c|c|c|c|c|c|}
\hline Patient & Gender & Age at last Examination (years) & Height & Common features & Additional features \\
\hline|| $\mid-2$ & Male & $50 y$ & $168 \mathrm{~cm}$ (normal) & Shortened fingers and toes & - \\
\hline|| $\mid-4$ & Male & $49 y$ & $157 \mathrm{~cm}(<-2.4 \mathrm{SD})$ & Shortened fingers and toes & $\begin{array}{l}\text { Radial deviation of the third finger, } \\
\text { radial deviation of the second and } \\
\text { third finger }\end{array}$ \\
\hline$\|||-5$ & Male & $47 y$ & $169 \mathrm{~cm}$ (normal) & Shortened fingers and toes & $\begin{array}{l}\text { Flexion contracture of the } 4 \text { nd } \\
\text { finger }\end{array}$ \\
\hline $\mathrm{IV}-2$ & Female & $30 y$ & $154 \mathrm{~cm}(<-2.4 \mathrm{SD})$ & $\begin{array}{l}\text { Shortened fingers and toes, } \\
\text { absence of middle phalanges } \\
\text { of the fifth finger, absence of } \\
\text { middle phalanges of the third } \\
\text { to fifth toes, fusion of middle } \\
\text { and terminal phalanges of } \\
\text { third to fifth toe, }\end{array}$ & $\begin{array}{l}\text { Radial deviation of the second } \\
\text { fingerbilateral shortening of } \\
\text { metacarpals bone } 3-5 \text {, bilateral } \\
\text { shortening of metatarsals bone } \\
3-4\end{array}$ \\
\hline IV-5 & Male & $19 y$ & $155 \mathrm{~cm}(<-2.5 \mathrm{SD})$ & $\begin{array}{l}\text { Shortened fingers and toes, } \\
\text { absence of middle phalanges } \\
\text { of the fourth toes. }\end{array}$ & $\begin{array}{l}\text { Radial deviation of the second } \\
\text { finger, }\end{array}$ \\
\hline
\end{tabular}

with BDA-1 phenotype in this family. Based on the number of affected individuals in this family, the LOD score was 1.5 which provided the supportive evidence for the pathogenicity (PP1_Strong) according to the ACMG / AMP guidelines. Statistical test for the mean digit length cannot be performed because of the lack of standard reference for fingers and toes of Chinese population. Finger 2 and 3 revealed that the affected individuals had relatively shortened fingers and toes to varied degree. We compared the height of each family members to the height growth chart for Chinese population. Non-affected individuals had normal stature. Some of the affected individuals had normal stature and some have short stature. The proband (IV-2) was a 30-year-old female, who presented with mild disproportionate short stature with a Height Standard Deviation Score (HSDS) of - 2.4SD. The radiograph of her hands showed varying degrees of shortening of the middle phalanx of the second to fifth fingers, and the middle phalanges in digit five was fused to the terminal phalanx as only one interdigital joint was visible. She also showed bilateral shortening of metacarpals bone 3-5. The radiograph of her feet showed shortening of all digits, the middle phalanges of third to fifth toe were fused to the terminal phalange (Fig. 2). She also had bilateral shortening of metatarsals bone 3-4. All of the other affected family members exhibited features consistent with BDA1. The toes of other affected individuals in the family were severely shortened and so were fingers (Fig. 3). Interestingly, short stature was not consistently presented among the affected individuals. The proband's uncle (III-4) and cousin (IV-5) presented with mild disproportionate short stature with a HSDS of $-2.4 S D \pm 0.3$, but her father's (III-2) and uncle's (III-5) heights were within normal range. In addition, the proband (IV-5), her father (III-2) and cousin (III-5) showed radial deviation of the second finger (Fig. 3a: III-2 and III-5). The uncle (III-5) showed radial deviation the 2 nd and 3 nd finger and flexion contracture of the 4nd finger (Fig. 3a). No other abnormalities were observed in the affected family members.

\section{Genetic analysis of whole exome sequencing}

Whole exome sequencing using the genomic DNA of proband IV-1(Fig. 1) was performed. In total, 850 million uniquely mapped reads with MAPQ $\geq 30$ were generated which covering $96 \%$ of exome target regions at least 20x. Exome sequencing called a total of 120,764 variants which excluded variants in non-functional variants such as intronic changes. A total of 16,040 variants were found in exonic and splice site regions. Among these variants, 1009 variants had the MAF less than 0.01 then neutral and benign variants were also omitted according to ClinVar. Based on the TGex software (LifeMap Sciences, USA), we found 17 variants existed in genes whose functions matched with known phenotypes. Variants from 6 genes associated with $I H H, N O T C H 1$, $H M N, A T R X, B B S 1$ and $L 1 C A M$ were extracted, leading to the identification of a novel variant in $I H H$ c.299A > G / p.Asp100Gly that co-segregated with the disease phenotype in the examined family (Fig. 4c).

The variant is not present in the Human Gene Mutation Database (http://www.hgmd.cf.ac.uk/ac/), HPSD (http://liweilab.genetics.ac.cn/HPSD/) and the dbSNP (http://www.ncbi.nlm.nih.gov/SNP/), nor it is present in the DNA samples from 200 normal or in the control databases (e.g. ExAC and gnomAD). The variant is located in $\mathrm{N}$-terminal signaling domain as the DD-peptidase zinc-binding domain of $\mathrm{IHH}$ protein. The functional predictions for c.299A > G / p.Asp100Gly were as 

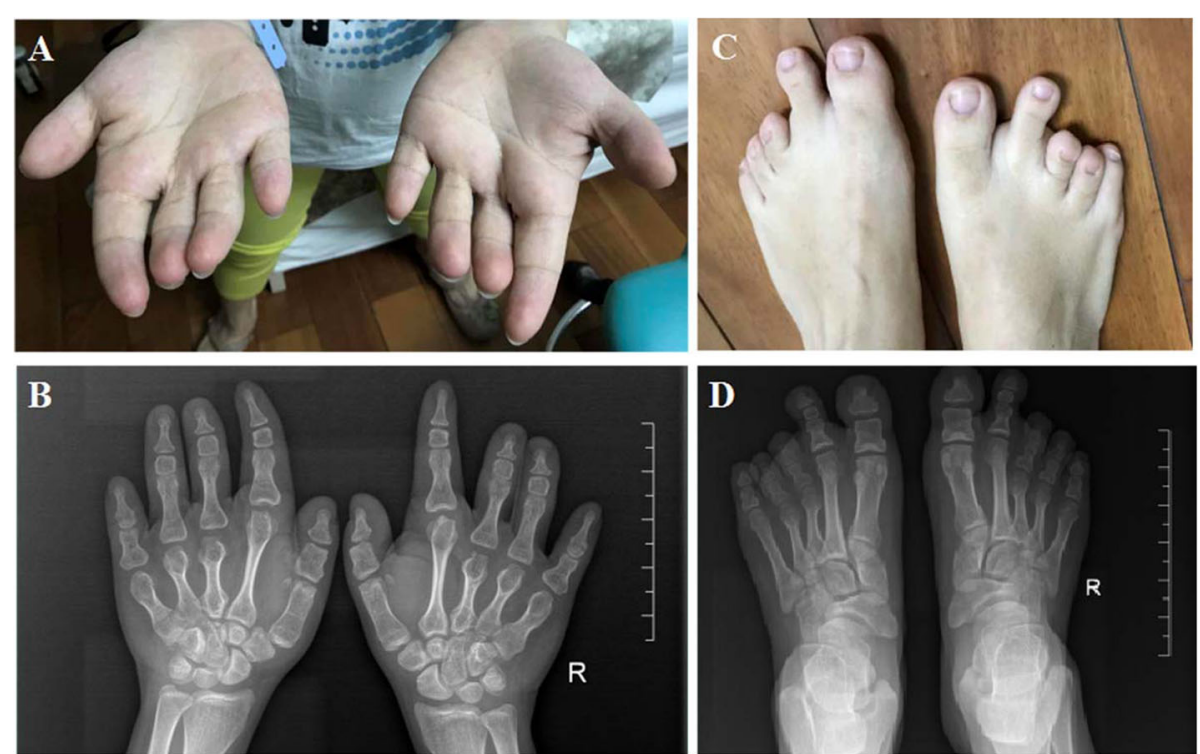

Fig. 2 a-d The appearance and radiological findings of the proband with brachydactyly type A1(BDA1). a showing shortened fingers and absence of middle phalanges of the fifth finger and radial deviation of the second finger. $\mathbf{b}$ Radiographic images of proband's hand: shortening of the middle phalanges of digits $\|-V$, fusion of middle and terminal phalanges of 5th finger, bilateral shortening of metacarpals bone 3-5. c showing short toes and absence of middle phalanges of the third to fifth toes. $\mathbf{d}$ Radiographic images of proband's foot: fusion of middle and terminal phalanges of third to fifth toe, bilateral shortening of metatarsals bone $3-4$

following: CADD score $=31$ (Damaging), SIFT score $=-$ 5.58 (Deleterious), PolyPhen2.0 score = 1 (Probably damaging) and Mutation Tasters (disease-causing). Further 3D structures of the wild type (WT) and mutant IHH were predicted using SWISS-MODEL (https://swissmodel.expasy.org/interactive). The result showed that the proportion of $\beta$-sheet would decrease and that of random coil increase in mutant protein compared to wild protein. In particular, domains 144-146 and 149-151 were predicted to be altered from $\beta$-sheets into random coils. The overall shape of IHH protein would be altered as shown in Fig. 5 which would consequently lead to reduced PTC1 binding and downstream signalling. It is revealed that the novel missense variant had deleterious effects. According to the AMP/ACMG guidelines for the interpretation of sequence variants [6], the novel variant is pathogenic (PM1, PM2, PM5, PP1_Strong, PP3, PP4).

\section{Discussion}

Brachydactyly type A1 is characterized by hypoplasia/ aplasia of the middle phalanges of digits $2-5$. IHH was the first identified gene to be associated with BDA1 [7]. The $I H H$ gene, which encodes a signaling protein of the Hedgehog family, is known for its role in endochondral

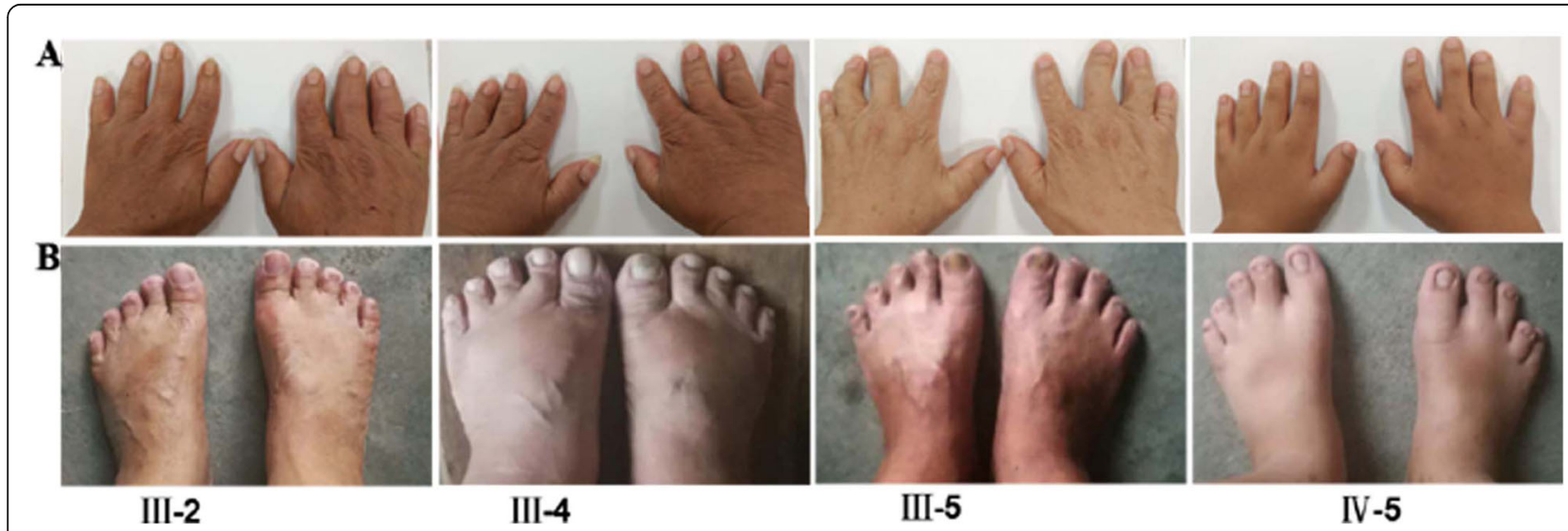

Fig. 3 Features of other affected family members with brachydactyly type A1 (BDA1). a showing shortened fingers and radial deviation of the second or/and third finger (III-2, III-5, IV-5) and flexion contracture of the 4nd finger (III-5). b showing abnormally shortened toes 


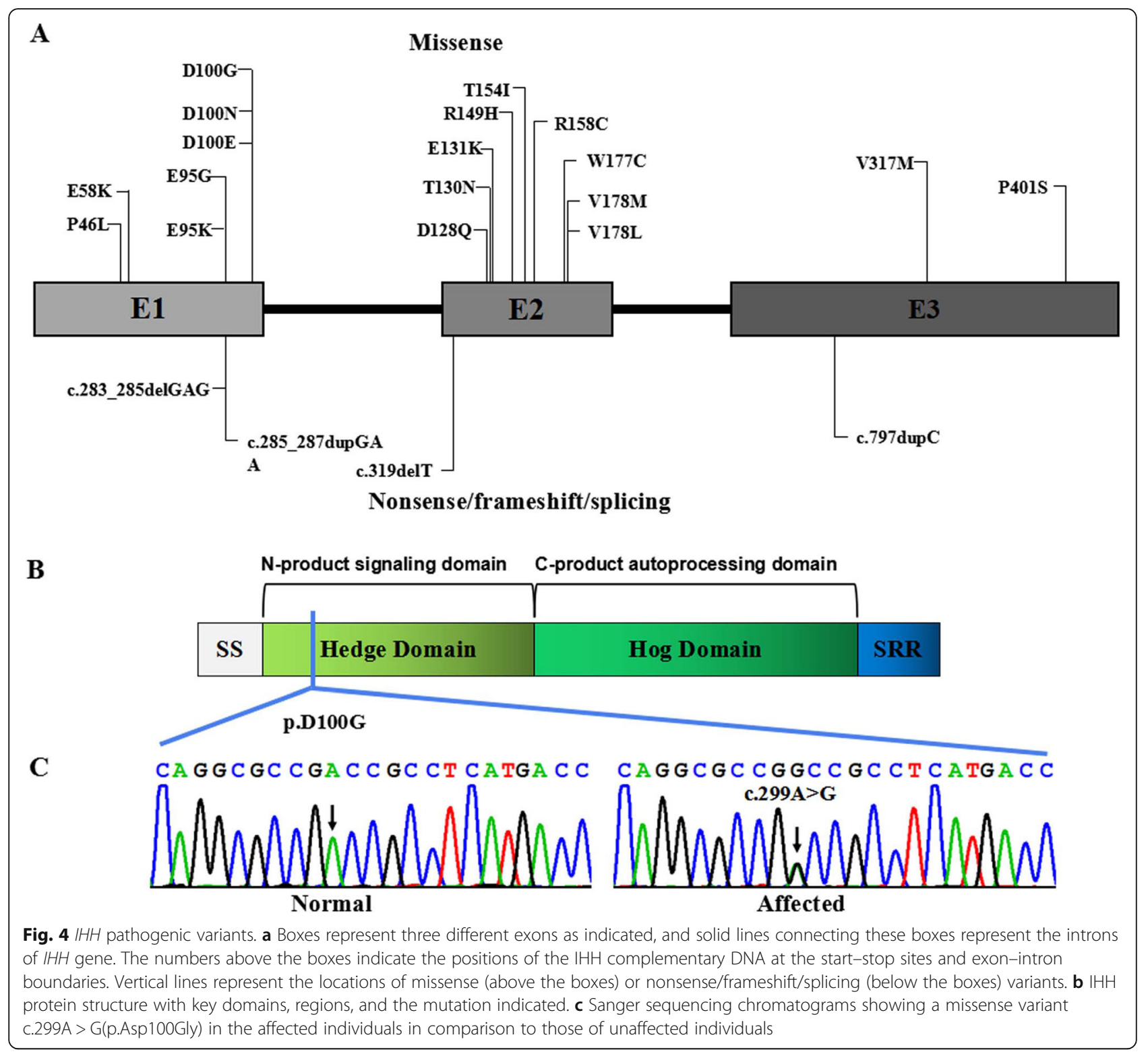

ossification: regulate the balance between growth and ossification of developing bones [5]. The IHH protein operates through a feedback control mechanism where IHH binds to the patched (PTC) receptor which functions in association with smoothened (SMO), in order to activate the GLI complex of transcription factors [8-10]. From there, these transcription factors continue to signal and regulate down-stream genes affecting patterning.

$I H H$ variants affect th signaling at multiple levels. It impairs chondrocyte maturation and proliferation, resulting in failure of osteoblast development in endochondral bones [7]. So far, about $14 \mathrm{IHH}$ pathogenic variants have been reported to be associated with $\mathrm{BD}$ [11-14] (Fig. 4). All of the pathogenic variants are restricted to the $\mathrm{N}$-terminal active fragment yet exhibit a variable outcome [4]. Variants associated with brachydactyly type A1 are known to affect codons 95, 100,131 , and 154 predominantly $[3,15,16]$. Based on the X-ray crystal structure of $\mathrm{IHH}$, McLellan, et al. showed that these residues are located within a calcium binding site, an important domain for mediating interactions with PTCH1, HIP1, CDO and GAS1 [17]. Previous studies showed that p.D100E affected the IHH interactions with PTCH1 and HIP1 which resulted in reduced capacity to induce cellular differentiation [16], and p.D100N changed the $\mathrm{Hh}$ local tertiary structure and intracellular fate [5], causing abnormal bone development and abnormal digit formation. The protein 3D modelling prediction of the new mutant (p.D100G) also suggested an overall structural 

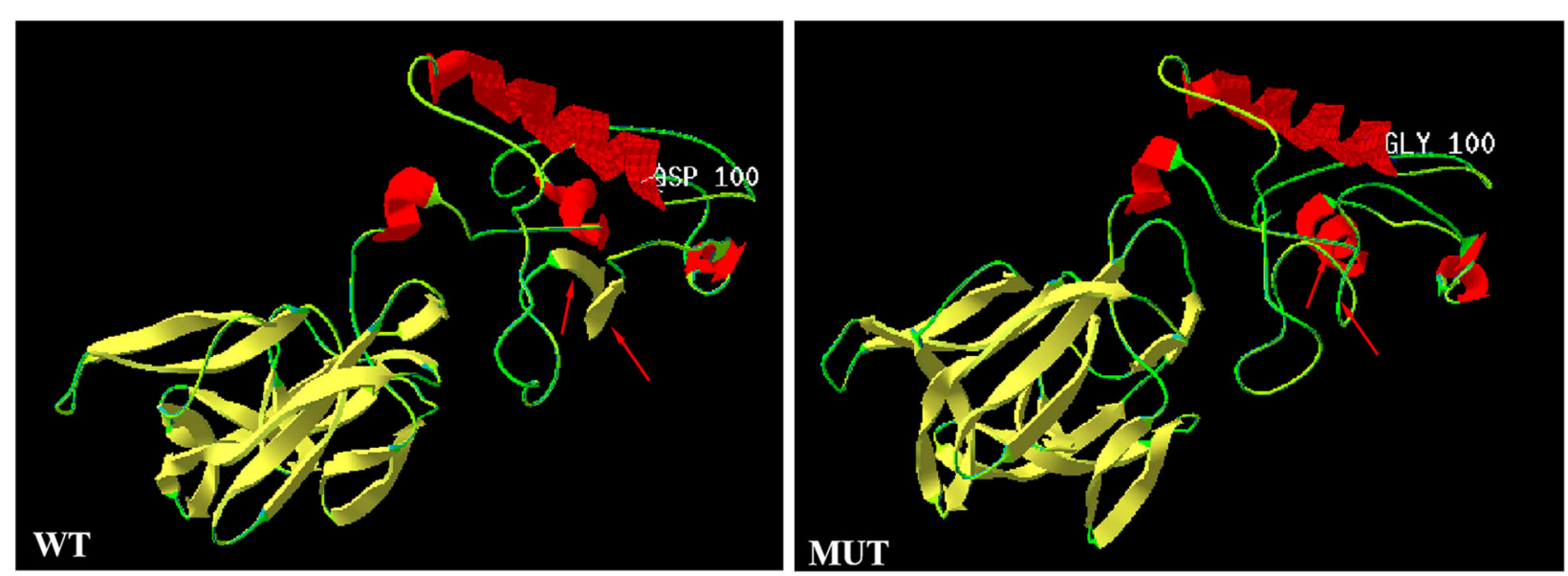

Fig. 5 Three-dimensional structure modeling predicted a decrease in the proportion of $\beta$-sheet regions, and an increase of random coil regions in mutant protein. The dimer alterations are indicated by an arrow. WT, wild-type; MUT, mutant-type

alteration, thus we suggest that the new mutant acted similarly to the p.D100E and p.D100N mutants which would affect Hh signaling at multiple levels, causing abnormal bone development and abnormal digit formation.

To date, six other BDA1-affected families of Italian, American, India, British and Chinese descent have been found to affect the same IHH codon at the position 100, demonstrating a mutational hot spot of $I H H$. The novel variant at the nucleotide position c.299 A > G of the $I H H$ gene results in a novel amino acid substitution (p.D100G) at the hotspot. This novel variant co-segregated with the BDA1 phenotype in this Chinese family and demonstrated high penetrance of this pathogenic variant in causing dactyl phenotypes. In addition, phenotypic variations were observed among affected family members in terms of the severity of affected phalanges and metacarpal/ metatarsal bones, demonstrating considerable intrafamilial phenotypic variability.

$\mathrm{IHH}$ is expressed in the prehypertrophic chondrocytes of cartilage, and regulates growth of bones by coordinating chondrocyte proliferation and differentiation [18]. Dysregulation of IHH could affect the growth of phalangeal bones, as well as the long bones which could subsequently affect body height.

Although short stature is often a component of brachydactyly, it has been reported infrequently in type A1. It was only presented in brachydactyly type A1 patients with the variants at $I H H$ Asp100 $[3,19$, 20]. Interestingly, Gao et al. reported that all affected subjects were shorter than unaffected subjects in the same family whereas short stature was only presented for some family members reported by Giordano et al. and McCreadyet et al. [3, 19, 20], suggesting an incomplete penetrance of short stature associated with IHH variants. Consistently, in this Chinese family with a novel variant at residue 100, short stature was not $100 \%$ penetrant: the proband (IV-2), proband's uncle (III-4), and cousin (IV-5) had short stature, whereas her father (III-2) and uncle (III-5) had normal stature. Pedigree studies provided the opportunity to identify co-determinants for human height. Gabriela et al. observed that heterozygous deleterious $I H H$ variants are more frequent in short stature cohort (1.6\%) in Brazilian and Spanish populations compared to the general population (0.017\% in gnomAD; $P<0.001)$ [20], supporting the notion that reduced IHH signaling may be responsible for a reduced growth of the long bones and short stature [3, 7]. We suggest that the variant on Asp100 would reduce IHH signaling capacity which consequently reduced the growth of the long bones, and resulting in short stature. Certainly, there are other factors involved in affecting the final stature of individuals with $I H H$ pathogenic variants. The role of $\mathrm{IHH}$ variants in non-syndromic short stature also needs further study.

\section{Conclusions}

In conclusion, a novel missense variant (c.299 A > G) affecting a mutational hotspot (residue 100) of $I H H$ was identified in a Chinese family affected by BDA-1. Sufficient evidence supported the pathogenicity of this novel variant. High penetrance for the phalange phenotype and variable expressivity were observed in this family. Short stature was only observed in a subset of affected family members. The findings of this report will further help our understanding the phenotype-genotype correlations of $I H H$ pathogenic variants and related disorders including brachydactyly type A1. 


\section{Abbreviations}

IHH: Indian Hedgehog; BDA-1: Brachydactyly type A1; BD: Brachydactyly; WES: Whole exome sequencing; WT: Wild type; MUT: Mutant; HSDS: Height Standard Deviation Score; HGMD: Human Gene Mutation Database: PTC: Patched Receptor; GATK: Genome Analysis Toolkit; SD: Standard Deviation; SMO: Smoothened

\section{Acknowledgements}

We are grateful to the family for participating in this study and thank Maggie Huang for editing the manuscript.

\section{Authors' contributions}

QY and YPS designed the study and drafted the manuscript; JW, QY, XXT, FS and $J L$ extracted, analyzed, interpreted the data, and collected the clinical data; QZ, XF, SY and MTL performed the targeted sequencing, analyzed and interpreted the data; YPS and QY participated in the study coordination and revised the manuscript. All authors read and approved the final version of the manuscript.

\section{Funding}

This work is partially supported by the "Eastern Scholar" Fund; the "Guangxi Bagui Scholar" fund; the Natural Science Foundation of China [grant number 81873633]; Major Research Plan of the Provincial Science and Technology Foundation of Guangxi [grant number AB16380214]; National key research and development program (2018YFC1002501) and the GeneScience Pharmaceuticals Co., Ltd. (Changchun, China). The funding body play no direct role in the design of the study, and collection, analysis, and interpretation of data, and in writing the manuscript.

\section{Availability of data and materials}

The data used and/or analyzed in the present report were deposited in the Sequence Read Archive (SRA) database. The data are accessible via the SRA accession: PRJNA612182; or via the links: https://www.ncbi.nlm.nih.gov/sra/ PRJNA612182; https://trace.ncbi.nlm.nih.gov/Traces/sra/?run=SRR11294037.

\section{Ethics approval and consent to participate}

All procedures in this study were approved by the Institutional Review Boards andEthics Committees of Guangxi Maternal and Child Health Hospital. Detailed written informed consent was obtained from all participants. In the case of children or those cognitively impaired and unable, written informed consent for participation in this study was obtained from the patients' parents or guardians.

\section{Consent for publication}

Written informed consent for publication of photographs, clinical and genetic data was obtained fromall participants. The parents /legal guardian of the children (under the age of 18) has signed written informed consent for publication of photographs, clinical and genetic data.

\section{Competing interests}

The authors declare that they have no competing interests.

\footnotetext{
Author details

${ }^{1}$ Genetic and Metabolic Central Laboratory, Birth Defect Prevention Research Institute, Maternal and Child Health Hospital, Children's Hospital of Guangxi Zhuang Autonomous Region, Nanning 530002, China. ${ }^{2}$ Department of Ultrasonography, Maternal and Child Health Hospital, Children's Hospital of Guangxi Zhuang Autonomous Region, Nanning 530002, China. ${ }^{3}$ Department of Gynaecology, Maternal and Child Health Hospital, Children's Hospital of Guangxi Zhuang Autonomous Region, Nanning 530002, China. ${ }^{4}$ Department of Medical Genetics and Molecular Diagnostic Laboratory, Shanghai Children's Medical Center, Shanghai Jiao Tong University School of Medicine, Shanghai 200127, China. ${ }^{5}$ Division of Genetics and Genomics, Boston Children's Hospital; Department of Neurology, Harvard Medical School, Boston, MA 02115, USA.
}

Received: 17 June 2019 Accepted: 17 March 2020

Published online: 24 March 2020

\section{References}

1. McCready ME, Sweeney E, Fryer AE, Donnai D, Baig A, Racacho L, et al. A novel mutation in the $\mathrm{HH}$ gene causes brachydactyly type A1: a 95-year-old mystery resolved. Hum Genet. 2002;111(4-5):368-7.

2. Fitch $\mathrm{N}$. Classification and identification of inherited brachydactylies. J Med Genet 1979:16:36-44

3. Gao B, Guo J, She C, Shu A, Yang M, Tan Z, et al. Mutations in $\mathrm{HH}_{\text {, encoding }}$ Indian hedgehog, cause brachydactyly type A-1. Nat Genet. 2001;28(4):386-8.

4. Byrnes AM, Racacho L, Grimsey A, Hudgins L, Kwan AC, Sangalli M, et al. Brachydactyly A-1 mutations restricted to the central region of the $\mathrm{N}$ terminal active fragment of Indian hedgehog. Eur J Hum Genet. 2009;17: 1112-20. https://doi.org/10.1038/ejhg.2009.18.

5. Ma G, Yu J, Xiao Y, Chan D, Gao B, Hu J, et al. Indian hedgehog mutations causing brachydactyly type A1 impair hedgehog signal transductionatmultiple levels. Cell Res. 2011;21:1343-57. https://doi.org/10.1038/cr.2011.76.

6. Richards S, Aziz N, Bale S, Bick D, Das S, Gastier-Foster J, et al. Standards and guidelines for the interpretation of sequence variants: a joint consensus recommendation of the American College of Medical Genetics and Genomics and the Association for Molecular Pathology. Genet Med. 2015:17:405-24.

7. Gao B, Hu J, Stricker S, Cheung M, Ma G, Law KF, et al. A mutation in Ihh that causes digit abnormalities alters its signalling capacity and range. Nature. 2009;458(7242):1196-200. https://doi.org/10.1038/nature07862.

8. Chen $Y$, Struhl G. Dual roles for patched in sequestering and transducing Hedgehog. Cell. 1996;87:553-63.

9. Marigo V, Johnson RL, Vortkamp A, Tabin CJ. Sonic hedgehog differentially regulates expression of GLI and GLI3 during limb development. Dev Biol. 1996;180:273-83.

10. Lee J, Platt KA, Censullo P, Ruiz i Altaba A. Gli1 is a target of sonic hedgehog that induces ventral neural tube development. Development 1997:124:2537-52

11. Salian S, Shukla A, Nishimura G, Girisha KM. Severe form of Brachydactyly type A1 in a child with a c.298G > a mutation in $\mathrm{HH}$ gene. J Pediatr Genet. 2017;6:177-80. https://doi.org/10.1055/s-0037-1599201.

12. Lodder EM, Hoogeboom AJ, Coert JH, de Graaff E. Deletion of 1 amino acid in Indian hedgehog leads to brachydactylyA1. Am J Med Genet A. 2008; 146A:2152-4. https://doi.org/10.1002/ajmg.a.32441.

13. Ho R, Mclntyre AD, Kennedy BA, Hegele RA. Whole-exome sequencing identifies a novel $\mathrm{HH}$ insertion in an Ontario family with brachydactylytype A1. SAGE Open Med Case Rep. 2018;6:2050313X18818711. https://doi.org/ 10.1177/2050313X18818711.

14. Vasques GA, Funari MFA, Ferreira FM, Aza-Carmona M, Sentchordi-Montané L, Barraza-García J, et al. $1 \mathrm{HH}$ gene mutations causing short stature with nonspecific skeletal abnormalities and response to growth hormone therapy. J Clin Endocrinol Metab. 2018;103:604-14. https://doi.org/10.1210/ jc.2017-02026.

15. Kirkpatrick TJ, Au KS, Mastrobattista JM, McCready ME, Bulman DE, Northrup H. Identification of a mutation in the Indian hedgehog $(\mathrm{IHH})$ gene causing brachydactyly type A1 and evidence for a third locus. J Med Genet. 2003;40:42-4

16. Liu M, Wang X, Cai Z, Tang Z, Cao K, Liang B, et al. A novel heterozygous mutation in the Indian hedgehog gene $(\mathrm{HH})$ is associated with brachydactyly type A1 in a Chinese family. J Hum Genet. 2006;51:727-31.

17. McLellan JS, Zheng X, Hauk G, Ghirlando R, Beachy PA, Leahy DJ. The mode of hedgehog binding to Ihog homologues is not conserved across different phyla. Nature. 2008;455:979-83. https://doi.org/10.1038/nature07358.

18. Minina E, Wenzel HM, Kreschel C, Karp S, Gaffield W, McMahon AP, et al BMP and Ihh/PTHrP signaling interact to coordinate chondrocyte proliferation and differentiation. Development. 2001;128:4523-34.

19. Giordano N, Gennari L, Bruttini M, Mari F, Meloni I, Baldi C, et al. Mild brachydactyly type A1 maps to chromosome 2q35-q36 and is caused by a novel IHH mutation in a three generation family. J Med Genet. 2003;40:132-5.

20. Hellemans J, Coucke PJ, Giedion A, De Paepe A, Kramer P, Beemer F, et al. Homozygous mutations in $1 \mathrm{HH}$ cause acrocapitofemoral dysplasia, an autosomal recessive disorder with cone-shaped epiphyses in hands and hips. Am J Hum Genet. 2003;72:1040-6.

\section{Publisher's Note}

Springer Nature remains neutral with regard to jurisdictional claims in published maps and institutional affiliations. 